\title{
Constraints in Adoption of Modern Vegetable Cultivation Practices in Bastar Plateau
}

\author{
Ashwini Kumar Tiwari ${ }^{1 *}$ and Jugul Kishor Tiwari ${ }^{2}$ \\ ${ }^{1}$ Fiji national university, College of Agriculture, Fisheries and Forestry, \\ Koronivia, Fiji Islands \\ ${ }^{2}$ Indira Gandhi Agricultural University, Raipur, Chhattisgarh, India
}

\begin{abstract}
A B S T R A C T
Keywords

Constraints,

Vegetable,

Improved practices,

Bastar plateau

Article Info

Accepted:

06 December 2017

Available Online:

10 January 2018

The present study was conducted in the three blocks, namely Turenar, Tahkapal and bastanar block of Bastar district. These blocks are inhabited by the tribes, particularly Bhatra, Gond, Halwa, Maria, Muria, who are normally doing subsistence farming. Farmers of these regions are doing only traditional farming. Among these three blocks, 12 villages were selected randomly i.e. four villages from each block. From each village 10 vegetable growers were randomly selected by random sampling method. The total no of respondent to this study were 120 vegetable growers. The average productivity of vegetable crops in Chhattisgarh is $130.16 \mathrm{q}$ per hectare which is below than the national average. It is mainly due to poor knowledge, facility as well as reluctant attitude of farmers in adopting the new technology. It is observed that a wide gap exist in production obtained and potential yield. Productivity per unit area can be obtained only by adopting improved varieties, hybrids as well as modern vegetable cultivation practices. The major bottlenecks in increasing production in this district were non availability of improved varieties (80\%), Disease and insect resistant varieties (78\%), high cost of seeds (77\%), improper dose of fertilizer (74\%), non-availability of skilled labour (74\%) and price fluctuation of produce (58\%), which discourages the farmers to adopt modern vegetable cultivation practices.
\end{abstract}

\section{Introduction}

In era of shrinking land holding, and more pressure per unit area of land, cultivation of fruit and vegetable has emerged as profitable venture. Cultivation of vegetable not only provide nutritional security, it also provides a substantial employment to rural people as well as open the door for export. Thus, plays an active role in increasing the livelihood condition of poor rural folks. Vegetables are one of the cheapest sources of natural protective food, contributing carbohydrates, vitamins and mineral in human diet (Choudhury, 2006). Vegetables are rich in vitamins and in comparison to other sources it is cheaper. Vegetable consumption provides taste, increase appetite, palatability and provides necessary fibre, essential for proper functioning of digestive system.

Vegetable cultivation has a number of added advantage like vegetable are of shorter duration, than cereal crop, so, more crops can 
be taken per unit area of land in a year, vegetable cultivation are helpful in diversification of agriculture, providing ample opportunities to conserve soil and moisture depletion. A farmer can fetch more prices for his produce in comparison to cereal crops from the small unit area of land, he can take more produce than other crops. Vegetable cultivation involves intensive cultural operations since sowing for marketing, providing regular employment opportunities to unemployed youth to farmer and farm family. At the same time perishable nature of vegetable demand skill and comprehensive planning for storage, movement, and distribution as well as processing of vegetable produce.

Nowadays, people are aware regarding their health proposition, as a result they want to add more and more fruit and vegetable in their food basket. Vegetable are cheapest source of carbohydrates, minerals and vitamins. Vegetables are now commercialized, but still traditional farming is done in far flung areas like Bastar Plateau in Chhattisgarh, which are normally inhabited by the tribes, particularly Maria, Muria, Gond, Bhatra, and Halwa, who are doing subsistence farming. Ninety seven per cent areas in Bastar Plateau are rain-fed. In Chhattisgarh, total area under vegetable cultivation is $3,77,212$ ha and production is $4,96,5331$ metric tonnes per hectare and productivity is 13.16 metric tonnes (Anonymous, 2012). It shows that there is tremendous scope to increase the productivity per unit area. Nowadays vegetable cultivation is highly commercialized, but there is still a wide gap between production realized and potential production. So, efforts have to be made by researchers, extension workers and policy makers to bridge this gap (George and Singh, 2006). By adopting improved techniques and high yielding varieties, production and productivity can be increased (Sahu et al., 2009). In vegetable cultivation, a number of technology has been developed, but farmers do not show keen interest in adopting this technology. So, to enhance the production and adoption of new farming technology it is imperative to know, why farmers are reluctant in adaptation of this technology. So, to know that what are the constraints faced by farmers in adoption of Modern practice of vegetable cultivation. This study was undertaken at Bastar Plateau.

\section{Materials and Methods}

The present study was conducted in Bastar district of Chhattisgarh in 2009-2011. For the purpose of study three blocks of Bastar viz. Bastar, Tahkapaland Turenar was purposely selected. These three blocks, are dominated by the tribe namely, Bhatra, Muria, Maria, Gond and Halwa. 12 villages were randomly selected from these three blocks, and from each village 10 vegetable growers were randomly selected by simple random sampling method. So the total number of 120 vegetable growers was selected.

A well-structured and pre-tested schedule was used to collect the information from the vegetable growers. In this study, an interview schedule, having 37 statements, regarding different constraints normally faced by the farmer were asked on different aspect of vegetable cultivation practice. The responses observed from the different farmers were divided into two categories i.e. yes and no. the statement having 'No' responses were given zero mark and the statement having "Yes" were given one mark. So, individual vegetable grower can get a maximum marks of 37 and thus minimum marks was zero.

\section{Results and Discussion}

The present investigation was categorized into four major constraints, faced by farmer in this far flung area. The major constraints faced by 
farmer, in vegetable cultivation are as follows: 1. Resource constraints, 2. Technological constraints, 3. Plant management constraints and 4. Storage and marketing constraints.

\section{Resource constraints in improved vegetable cultivation practices}

The major constraints, in this area is nonavailability of resources, Table 1 reveals that the major constraints faced by the farmers in this area is availability of seed of improved varieties $(80 \%)$ is the first resource constraints. The second (78\%) and third constraints $(77 \%)$ are the non-availability of disease and pest resistant varieties, as well as high cost of seeds. Farmers are also unaware of seed treatment and its effect on crop yield, beside it high cost of fertilizer is one of the major bottleneck in applying sufficient doses of fertilizer, (75\%), which ultimately hampering the production, other factors which re preventing the farmer in adoption of recommended vegetable cultivation practices are, non-availability of fertilizer (675), labour availability in peak season (64\%) as well as scattered and small holding (63\%).

The similar result was also reported by Dhillon and Kumar (2004), that high cost of seed and lack of improved seed varieties were constraints faced by the farmer. Mandeep Sharma (2014) also opined that high cost of chemicals for seed treatment, is a major constraints for non-adaptation of modern cultivation practices.

\section{Technology constraints in improved vegetable cultivation practices}

It is cleared in Table 2, Three fourth of respondents $(74 \%)$ were unaware regarding importance of fertilizer, to the crop, farmers were not applying proper dose of fertilizer, second most important constraints were the lack of knowledge, on proper method of fertigation $(70 \%)$ third most important constraints faced by the farmers, are knowledge of improved varieties (68\%), as we know, most of the improved varieties are fertilizer responsive, improver fertigation leads to less yield, other major technological constraints faced by the farmers are lack of availability of publication of modern technique of vegetable farming $(65 \%)$, lack of farmers training on modern vegetable production technique (63\%), lack of soil testing facility are the other constraints faced by the farmers in field. These findings were partially supported by Meena (2003) and Rai et al., (2010).

\section{Plant management constraints in improved vegetable cultivation practices}

From the analysis of Table 3, the major constraints emerge from the responses of farmer on plant management parts is nonavailability of skilled labour (74\%) during peak season. High cost of weedicides (58\%), high cost of insecticide/fungicide, improper knowledge on proper dose of weedicide/ insecticide/fungicide $(55 \%)$, poor response of chemicals (52).

These are in accordance with findings of Dhillon and Kumar (2004). The data further reveals that unavailability of chemicals (weedicide/ fungicide/ pesticide). Technical knowledge on weed application (50\%), knowledge on weedicide, lack of technical knowledge, non-availability of proper spraying instruments, are the major constraints in adoption of improved cultivation practices of vegetables. The inferences drawn from the Table 3 also says that financial problem $(57 \%)$ is also one of the major bottlenecks in adoption of improved plant management, during adoption of modern vegetable cultivation practices. These finding are in accordance to findings of Kumar (2008) and Mandeep Sharma (2014). 
Table.1 Resource constraints

\begin{tabular}{|c|l|c|c|c|}
\hline \multicolumn{2}{|c}{ Constraints } & Frequency & $\%$ & Rank \\
\hline $\mathbf{1}$ & Availability of seed of improved variety & 96 & 80 & I \\
\hline $\mathbf{2}$ & Availability of disease/ pest resistant varieties & 94 & 78 & II \\
\hline $\mathbf{3}$ & Knowledge on seed treatment (chemicals) & 90 & 75 & IV \\
\hline $\mathbf{4}$ & High cost of seed & 92 & 77 & III \\
\hline $\mathbf{5}$ & High cost of fertilizer & 90 & 75 & IV \\
\hline $\mathbf{6}$ & Labour availability in peak season & 77 & 64 & VI \\
\hline $\mathbf{7}$ & Non-availability of fertilizer & 80 & 67 & V \\
\hline $\mathbf{8}$ & Land holding (scattered, small) & 75 & 63 & VII \\
\hline
\end{tabular}

Table.2 Technological constraints

\begin{tabular}{|c|l|c|c|c|}
\hline \multicolumn{1}{|c}{ Constraints } & \multicolumn{3}{c|}{$(\mathrm{N}=120)$} \\
\hline $\mathbf{1}$. Frequency & Rank & Rank \\
\hline $\mathbf{2}$ & Knowledge about improved varieties & 82 & 68 & III \\
\hline 3 & Proper disease and pest management & 65 & 54 & VII \\
\hline 4 & Proper fertigation & 89 & 74 & I \\
\hline 5 & Method of fertigation & 84 & 70 & II \\
\hline 6 & Training on modern vegetable production technique & 76 & 63 & V \\
\hline & $\begin{array}{l}\text { Availability of publication on modern technique of } \\
\text { vegetable farming }\end{array}$ & 78 & 65 & IV \\
\hline 7 & Soil testing facility & 70 & 58 & VI \\
\hline
\end{tabular}

Table.3 Plant management constraints

\begin{tabular}{|c|l|c|c|c|}
\hline \multicolumn{1}{|c}{ Constraints } & \multicolumn{3}{|c|}{ (N=120) } \\
\hline $\mathbf{1}$ & Krequency & $\%$ & Rank \\
\hline $\mathbf{2}$ & Kechnicdge on weedicides & 55 & 46 & VII \\
\hline $\mathbf{3}$ & High cost of weedicides & 60 & 50 & VI \\
\hline $\mathbf{4}$ & High cost of insecticide/ fungicide & 68 & 58 & II \\
\hline $\mathbf{5}$ & $\begin{array}{l}\text { Unavailability of chemical (weedicide/ fungicide/ } \\
\text { pesticide) }\end{array}$ & 56 & 47 & VI \\
\hline $\mathbf{6}$ & Difficulty in diagnosis of disease and insect pest & 69 & 58 & II \\
\hline $\mathbf{7}$ & Availability of proper spraying instruments & 55 & 46 & VII \\
\hline $\mathbf{8}$ & Lack of technical know how & 42 & 35 & VIII \\
\hline $\mathbf{9}$ & $\begin{array}{l}\text { Knowledge on proper dose of weedicide/ insecticide/ } \\
\text { fungicide }\end{array}$ & 66 & 55 & IV \\
\hline $\mathbf{1 0}$ & Poor response of chemicals & 62 & 52 & V \\
\hline $\mathbf{1 1}$ & Non-availability of skilled labour & 74 & 62 & I \\
\hline $\mathbf{1 2}$ & Financial problem & 68 & 57 & III \\
\hline
\end{tabular}


Table.4 Storage and marketing constraints

$(\mathrm{N}=120)$

\begin{tabular}{|c|l|c|c|c|}
\hline S.No & \multicolumn{1}{|c|}{ Constraints } & Frequency & $\%$ & Rank \\
\hline $\mathbf{1}$ & Poor shelf life & 55 & 46 & VII \\
\hline $\mathbf{2}$ & Lack of cold storage & 49 & 41 & IX \\
\hline $\mathbf{3}$ & Lack of market facility in nearby areas & 47 & 39 & X \\
\hline $\mathbf{4}$ & Roads in poor conditions & 60 & 50 & V \\
\hline $\mathbf{5}$ & Exploitation by commission agents & 65 & 54 & II \\
\hline $\mathbf{6}$ & Non-standard weighing procedures & 62 & 52 & IV \\
\hline $\mathbf{7}$ & Price fluctuation & 70 & 58 & I \\
\hline $\mathbf{8}$ & Unattractive price & 52 & 43 & VII \\
\hline $\mathbf{9}$ & Poor transportation facilities & 63 & 53 & III \\
\hline $\mathbf{1 0}$ & High cost of transportation & 57 & 48 & VI \\
\hline
\end{tabular}

Graph.1

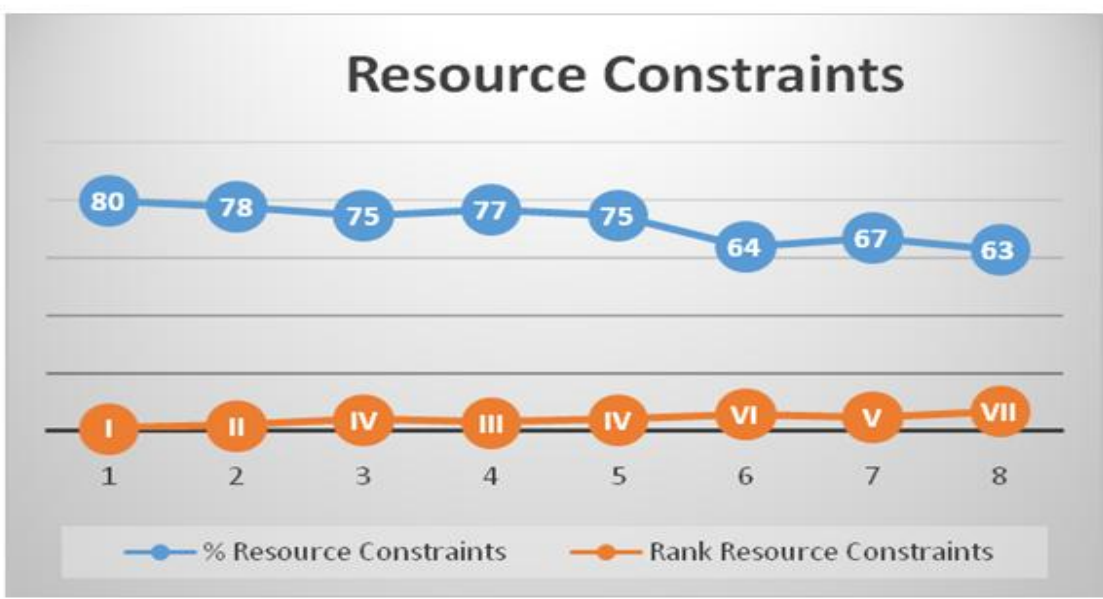

Graph.2

\section{TECHNOLOGY CONSTRAINTS}

ब\% Technological Constraints $₫$ Rank Technological Constraints

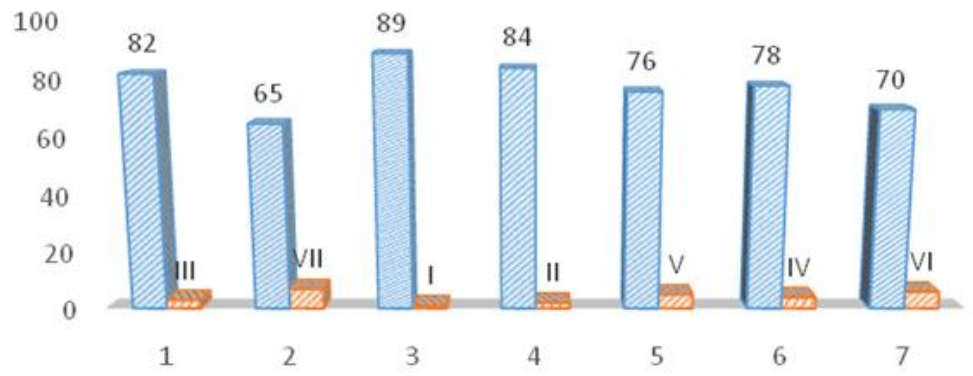




\section{Graph.3}

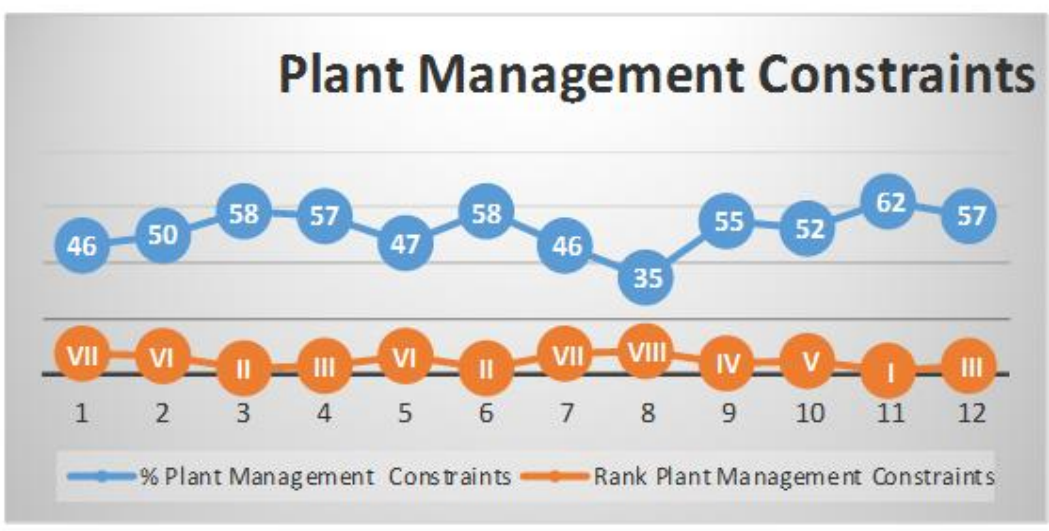

Graph.4

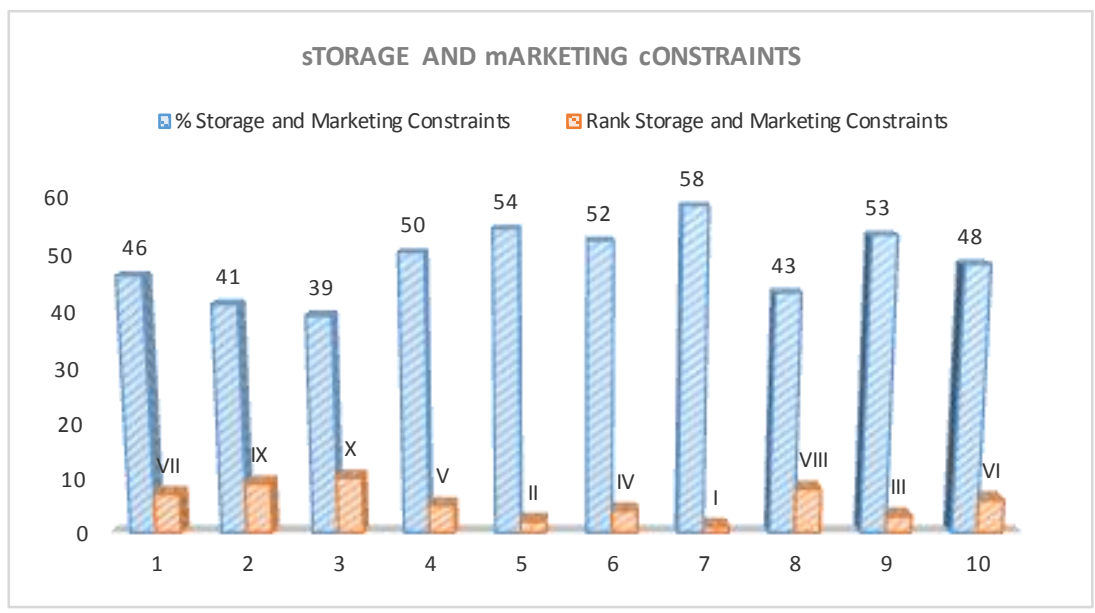

Storage and marketing constraints in improved vegetable cultivation practices

Analysis of Table 4, reveals that continuous price fluctuation (58\%) is the major bottleneck in adoption of improved cultivation practices of vegetables. Beside it exploitation by commission agent (54\%), poor transport facility $(53 \%)$, non-standard weighing procedures (52\%), poor condition of road $(50 \%)$, high cost of transportation (48\%), poor shelf life $(46 \%)$ and sprouts in vegetables, are the constraints which discourage farmers in adopting modern vegetable cultivation practices. Data from Table 3 also reveals unavailability of cold storage (41\%) and lack of market facility in nearby areas (39\%) also discourages the farmers to adopt modern vegetable cultivation practices. These findings are in conformity with the findings of Ghandi et al., (2008).

\section{Suggestion to overcome these constraints is as follows}

Basic input to the farmers should be provided timely and in advance of cropping season.

Extension worker should conduct demonstration in farmers' field, Kisanmela should be organized at the site of demonstration.

Financial assistance and subsidy should be 
provided timely to the farmer.

Poor irrigation facility in Bastar region, so more area should be covered under irrigation.

Better marketing as well as transportation facility should be provided to the farmer.

Training as well as extension programme should be well planned and before cropping season.

Stringent measures should be taken against commission agents who are exploiting farmers.

Strengthening of storage infrastructures and make them available to the farmer at cheaper rate.

This study reveals that non-availability of improved variety, disease free seeds, high cost of chemicals (weedicide/ fungicide/ pesticide), timely availability of chemicals, lack of knowledge on seed treatment, lack of Skilled labour, technical knowledge gap, financial problem, poor shelf life of vegetables, inappropriate equipment's, poor storage facility, poor market infrastructure, less support price and price fluctuation were the main constraints faced by the vegetable grower in the adoption of recommended vegetable cultivation practices by the vegetable growers, therefore planners should give importance to major constraints like technical literacy, infrastructure development and strengthening storage and marketing facility.

\section{References}

Anonymous, 2012. Status of horticulture in Chhattisgarh, (Pub. By) Directorate,
Horticulture and farm forestry, Chhattisgarh.

Choudhury, B., 2006. Vegetables, $2^{\text {nd }}$ edition, National Book Trust, India.

Dhillon G. S. and Kumar K. 2004. "Adoption of improved Metha cultivation practices". Indian J. Ext. Edu., Vol. 40, pp. 40-43.

George, S., and Singh A. 2006. "Vegetable for health and nutritional security" Yojanm, Vol-40, pp. 36-40.

Ghandi, V.R., Hanchinal S N, Shivamurthy M and Shailaja H. 2008. "Adoption of integrated pest management practices among tomato growers", Karnataka J. Agric. Sci., Vol-21, pp. 17-19.

Kumar, M., 2008. "Role of the Punjab state farmers commission in promoting the cultivation of vegetable and oilseed crops" Msc. Thesis, Punjab Agricultural University, Ludhiana, India.

Meena, K. C., 2003. Constraints faced by the farmers in adoption of improved cultivation of cabbage in Udaipur district of Rajasthan. Ind. Res. J. Ext. Edu., 3(2): 69-71.

Rai, D. P., and Singh. Bhupendra 2010. Extents of knowledge and constraints in cotton production technology in Madhya Pradesh. Ind. Res. J. Ext. Edu. 10(2): 7880.

Sahu, R. P., Sachan V. K, Singh, Raman Jeet and Singh Khilendra, 2009. Knowledge gap of farm women in vegetable cultivation. Journal of communication studies, 27(2): 83-87.

Sharma, Mandeep 2014. Constraints in adoption of recommended practices of vegetable crops. Ind. J. Ag. Sci. Vet. Med., 2(3): 6672.

\section{How to cite this article:}

Ashwini Kumar Tiwari and Jugul Kishor Tiwari. 2018. Constraints in Adoption of Modern Vegetable Cultivation Practices in Bastar Plateau. Int.J.Curr.Microbiol.App.Sci. 7(01): 820-826. doi: https://doi.org/10.20546/ijcmas.2018.701.100 